\title{
17
}

\section{Exploring hybridity in housing: Lessons for appropriate tenure choices and policy}

\author{
Louise Crabtree
}

\section{Introduction}

Housing for Aboriginal and Torres Strait Islander peoples is an ongoing focus of public policy, which recently has been oriented towards the twin objectives of transitioning community housing into arrangements mirroring public housing, and the creation of mortgagee home ownership. Within this policy landscape, this contribution reflects on research that is concerned with exploring perpetually affordable housing and community benefit in diverse contexts.

The research rests on a combination of radical democracy, complexity theory, and work on diverse or hybrid economies. These frameworks offer a coherent suite of considerations focused on diversity and contextuality with regard to community governance, knowledge, and economic articulations. These considerations are relevant as they allow for engaging with diverse community and organisational objectives and capacities within coherent guiding principles and research heuristics. Exploring these frameworks within housing provision has led to engagement with the community land trust (CLT) sectors in the United States of America and the United Kingdom. Both sectors 
are concerned with substantial and ongoing community input into the provision of diverse housing options that respond effectively to community need; as such, both sectors are characterised by the dual objectives of community benefit and perpetually affordable housing (Crabtree et al. 2012).

The research documented here was undertaken through the second of two consecutive projects supported by the Australian Housing and Urban Research Institute (AHURI). It focused on the relevance and articulation of housing based on community benefit and perpetual affordability for Aboriginal and Torres Strait Islander housing in New South Wales (NSW) and the Northern Territory (NT). To address the question in two differing contexts, the specific research tasks were developed according to local objectives and concerns. The projects worked with Aboriginal community organisations under endorsement of their executives, with research methods developed with organisational staff in light of executive direction. In both jurisdictions, organisational staff members were involved in and/ or responsible for discrete research tasks, enabling appropriate data collection and interpretation. The protocols, case studies, methods and outputs of the projects were guided, reviewed and endorsed by two Indigenous Advisory Groups, one per jurisdiction.

\section{Fostering housing diversity and discussion}

The iterative and contextual methods created a diverse range of research outputs alongside the core AHURI research report. In NSW these were a renewable, inheritable 99-year lease between the community organisation and individual households; financial modelling based on an indicative lease price and local household data; and a decision-making tool to help other organisations think through whether they need or want to diversify the housing options they offer their residents. These outputs were the result of the partner organisation's desire to create a housing tenure option that acted like mortgagee home ownership without exposing the household or the community organisation to unacceptable risks. Hence the price point for the lease was set according to local Aboriginal residents' incomes and capacity to sustain a moderate mortgage, and the lease had a tailormade, two-year initial period created to act as a 'testing of the waters' 
for both the resident and the organisation. This allowed a period for gauging the household's financial capacity and both parties' general satisfaction with the arrangement prior to the resident seeking and committing to the financial obligation of a mortgage. The use of a longterm lease ensures the underlying title remains with the community organisation, providing a buffer against loss of the house from the community should the resident be unable to sustain their tenancy. This was based on member communities' previous experience with home ownership schemes that had led to a loss of housing stock from the sector to the open market.

In the NT the research generated a survey of Town Camp residents' experiences of governance and housing before and since the Australian Government's Northern Territory Emergency Response (the Intervention), and aspirations for the future; a housing terminology brochure for residents; schematic diagrams of Camp governance before and after the Intervention; and a legal review of the issues emerging from consideration of long-term leases between households and their relevant housing organisation, whether an Aboriginal Corporation or a Housing Association. This suite of outcomes was generated by a sense that any discussion of tenure must first pay heed to prior and ongoing community experience, governance and expertise, and be built on communities' knowledge and aspiration for the future. The subsequent survey of 150 households across the relevant communities revealed a primary desire to see community governance and control reinvigorated.

Echoing previous research such as that of Memmott et al. (2009), issues such as community, stability, dignity and autonomy featured far more prominently in Town Camp residents' comments than did expectations of capital gain through housing. However, the latter remains a core federal housing policy objective and rationale regarding Aboriginal and Torres Strait Islander home ownership (FaHCSIA 2010). The potential community impact of excising individual housing lots from community control to enable mortgagee home ownership for selected households was a frequently raised concern amongst residents, and one that was felt not to have been acknowledged or addressed by current government policy imperatives. Moreover, there was much confusion created by a policy focus on 'ownership' when many households and communities already feel a sense of ownership due to their current perpetual community leases from government, multigenerational 
residency, and the presence of traditional owners amongst many communities. This confusion was the trigger for the creation of a housing terminology brochure that community researchers drafted and provided to residents after the survey, to inform discussion and help residents and communities develop a position in response to policy. As with the NSW case study, the retention of underlying title by relevant Aboriginal community entities was a primary concern.

\section{Core principles emerging from diversity}

The core concerns of the two case studies were brought together to develop appropriate overarching outputs. The first of these was a decision-making tool developed initially in and for the NSW context in collaboration with the NSW partner, but also endorsed by the NT Advisory Group as of use to communities in that jurisdiction. The tool broke the decision-making process down into a series of eight questions, with each corresponding to a series of talking points, relevant extant documents, and cross-references to related sections of both the tool and the Australian Community Land Trust Manual (Crabtree et al. 2013). The steps are:

1. Who can decide?

2. Community and household aspirations

3. Is a new program needed?

4. Organisation health check

5. Current stock characteristics

6. New program elements

7. Policy, tenure and legal settings

8. Design objectives and costs.

Building on the two case studies, a tenure model was described which could capture core principles without prescribing a particular legal arrangement. The principles of the model are:

1. Retention of an interest in the property by the relevant Indigenous organisation.

2. Determination and implementation of an appropriate legal agreement according to context and aspirations. 
3. Inclusion of an upfront price and ongoing administration fee set according to aspirations, capacity and objectives.

4. Articulation of repairs and maintenance, inheritance, use, etc. in the legal agreement.

5. Articulation of any equity treatment at termination of the agreement in the legal agreement.

This is a core contribution of the research, as it provides a coherent framework for enabling operational diversity; in this, tenure is the tool or outcome of a community process, not an objective in and of itself. This allows for a diversity of operational objectives and legal forms, including resident equity input if desired and appropriate. A single organisation might offer a range of options within its portfolio, addressing bottlenecks in local housing created by a lack of appropriate housing choices. Further, the same basic legal arrangement, such as a long-term lease between a community organisation and a household, could be amended to provide a diversity of arrangements with regard to equity, repairs and maintenance, and other such considerations. To help illustrate this, the research team created a tenure spectrum diagram showing the axes along which an organisation might like to arrange its operational parameters (see Fig. 17.1). As part of this, the team tried to start moving the language away from 'renting' or 'owning' as these terms are too simplistic to capture the nuance of how many communities experience their residency, and convey problematic associations regarding the underlying relationships or economic arrangements tied up in housing tenure. The terms adopted for the purpose of the diagram were non-equity, limited-equity and market-equity; however, more appropriate language might emerge over time. 


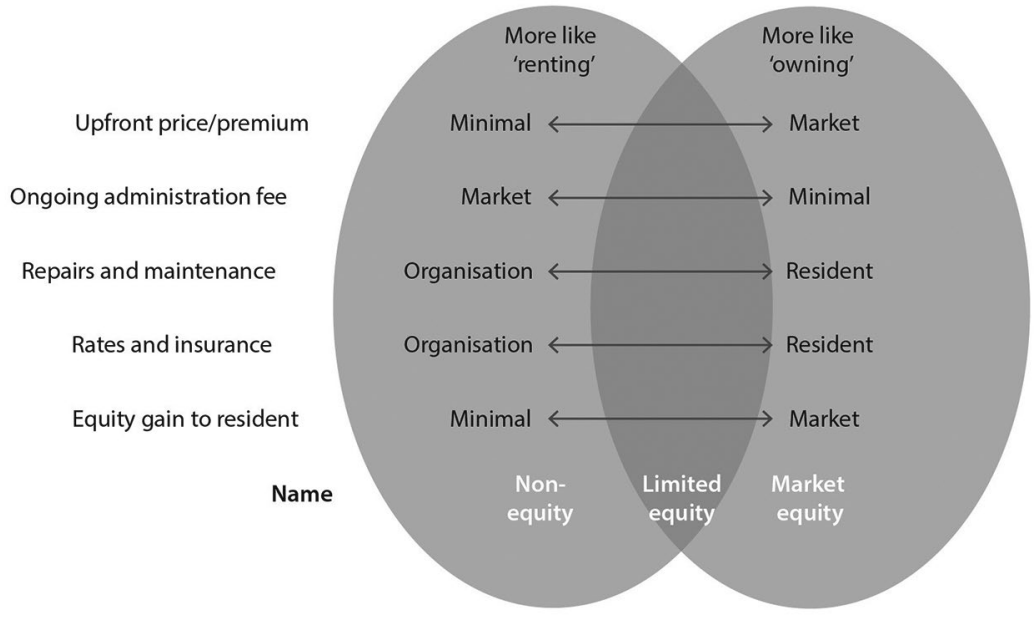

Fig. 17.1 A spectrum of housing options according to key variables Source: Crabtree et al. (2015: 6)

\section{Implications for process and policy}

Both jurisdictions highlighted the need and relevance for accessible and streamlined processes for lodging an expression of interest or applying to buy housing, as community organisations felt that current processes and policies (where these exist) were unclear. As with the outputs described above, it was seen to be important that any such process reflect community consideration. Fagan (2012) documented an expression of interest process currently being facilitated by the government in the context of Section 19A leases amongst selected communities in the NT. That process could present a relevant example for communities wishing to lease directly to their households, and could be similarly supported by government if this was a policy imperative.

The models outlined above highlight numerous avenues for policy support, where this supports the functions and objectives of the model, rather than asserting or assuming a particular tenure form. In addition to government support of an appropriate expression of interest or application process, the model highlights the need for an accessible information service; various forms of funding; organisational training or capacity building; appropriate governance arrangements; appropriate asset management strategies; and termination of subleases 
to government where these are in place, or similarly the removal of any caveats found to be impediments (see Crabtree et al. 2015 for fuller discussion of policy implications). In these, the determination of 'appropriate' must occur in genuine discussion with community, rather than in deference to top-down economic efficiency measures. The Papakāinga housing toolkit developed by Tauranga City Council (2013) to facilitate Māori housing in the Auckland region is a relevant example, as it consciously highlights the strengthening of the overall efficacy of the process and outcomes though building knowledge at each step (see Fig. 17.2). This is a core lesson for policy making in this space in Australia.

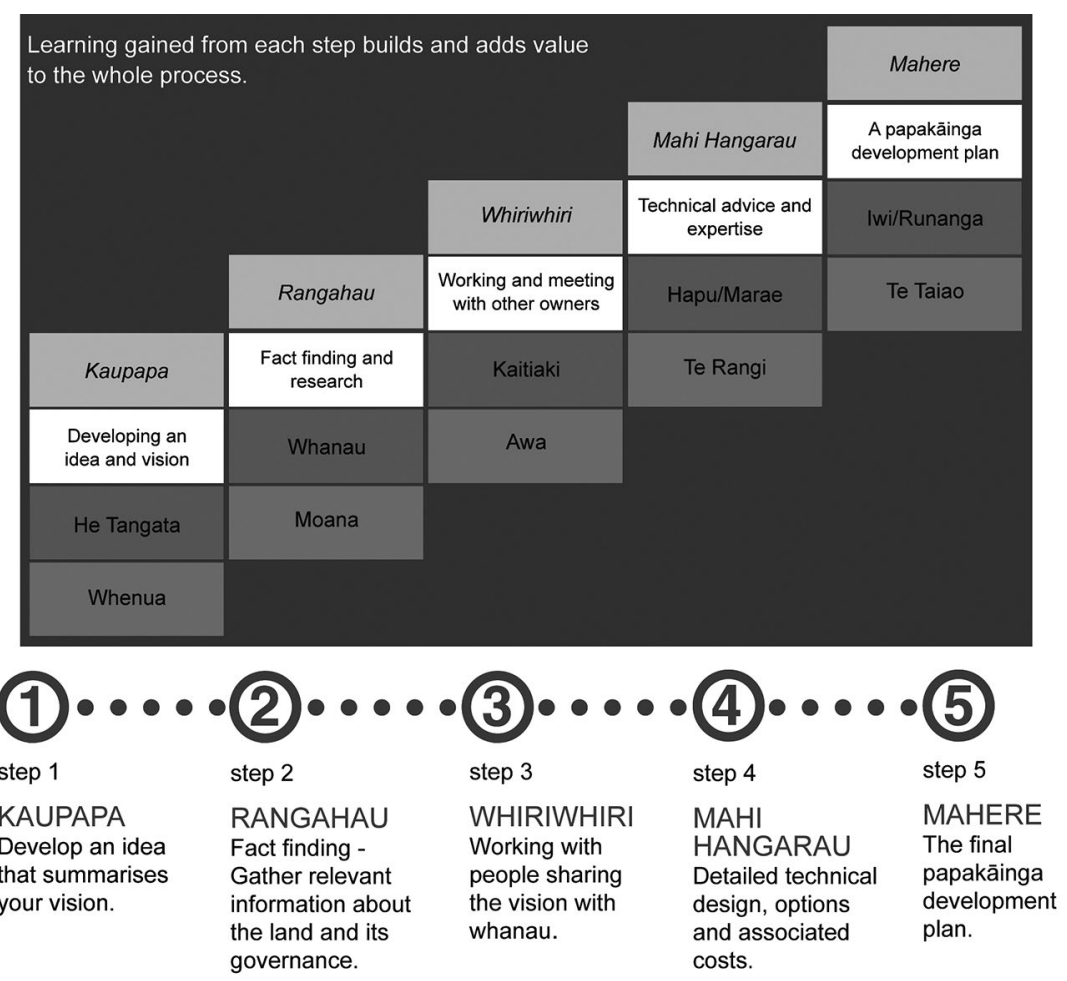

Fig. 17.2 Steps in the Tauranga Papakāinga housing toolkit

Source: Tauranga City Council (2013: 2, 4), with Joint Agency Group members: Tauranga City Council, Western Bay of Plenty District Council, Environment Bay of Plenty, Housing New Zealand Corporation, Te Puni Kōkiri, and, the Waikato Maniapoto and the Waiariki District Māori Land Courts. 
The current policy landscape is dominated by the twin objectives of moving Aboriginal and Torres Strait Islander housing into line with public housing, and the promotion of mortgagee home ownership on Aboriginal and Torres Strait Islander lands. On the latter, FaHCSIA's (2010: 18) core concern was:

How can Government achieve the right balance between facilitating home ownership for Indigenous Australians as an economic opportunity and supporting home ownership as a means to help build individual and social responsibility?

That policy question highlights two potentially troubling assumptions or expectations. First is the assumption that home ownership will lead to economic development; in the case of communities that can experience low and unstable employment levels, and that may wish to restrict the pool of eligible buyers to community members or other appropriate individuals, this seems a misguided proposition. In such situations, the potential for either capital gains through ownership and resale, or business development on the basis of securitisation would seem low, and lending against housing in such situations would seem risky. It would seem that rather than exposing households and communities to risk and possible asset loss, economic development would best be pursued through appropriate economic development, education, community development and employment strategies rather than through tenure reform. Second is the assertion of tenure reform as a disciplinary measure, implying an inherent deficit of responsibility amongst communities, requiring as its remedy the promotion of a neoliberal citizen engaged in market-based forms of housing. In such policy formulations, there is no focus on strengthening culture and community, promoting health, fostering stability, or any of the other functions of housing. Moreover, such blanket approaches allow no room for the diversity of Aboriginal and Torres Strait Islander communities' and households' objectives for housing and communities, which may or may not align with federal policy objectives.

There is significant, ironic contradiction between the policy imperatives for Aboriginal and Torres Strait Islander housing and those for the broader housing sector. In direct contrast to the Aboriginal and Torres Strait Islander housing sector, the broader affordable housing sector is witnessing policy movement towards community housing providers as the primary delivery mechanism. Similarly, while the Aboriginal and 
Torres Strait Islander sector is subject to manoeuvres towards marketbased mortgagee home ownership, the broader housing market is seeing investigation of various intermediate tenure options, in which equity and obligations are shared between the resident and either the government or a community housing provider. These models of shared equity home ownership (e.g. Regional Development Australia 2014) have the potential to provide submarket ownership opportunities, and ideally avoid the levels of mortgage stress and arrears generated overseas by predatory mortgage lending practices amongst marginal communities. Indeed, foreclosure studies of the community land trust sector in the United States of America have shown foreclosure rates below that of the open market during the mortgage crisis, while housing low- to moderate-income households (National CLT Network 2008; Misak 2009; Thaden 2010, 2011).

Perhaps the most interesting model of shared equity housing is Michael Stone's (2009) 'resident-saver' model, which is based on housing built by the government being held by a cooperative or mutual housing association. As with all cooperative housing, ownership of a share in the cooperative confers the right to reside in one of the cooperative's housing units - let's say, a house on community land. Shares carry a nominal value, say, a dollar, and the resident pays an administration fee to the cooperative to cover any ongoing costs such as maintenance. This is similar to how cooperative rental housing currently operates. The twist is that on top of the administration fee, the resident pays an additional regular amount which is deposited in an affiliated investment vehicle, such that the total of this and the administration fee is no more than 30 per cent of the gross household income. If and when the resident decides to leave, their equity return is the return on that investment (see Fig. 17.3). 


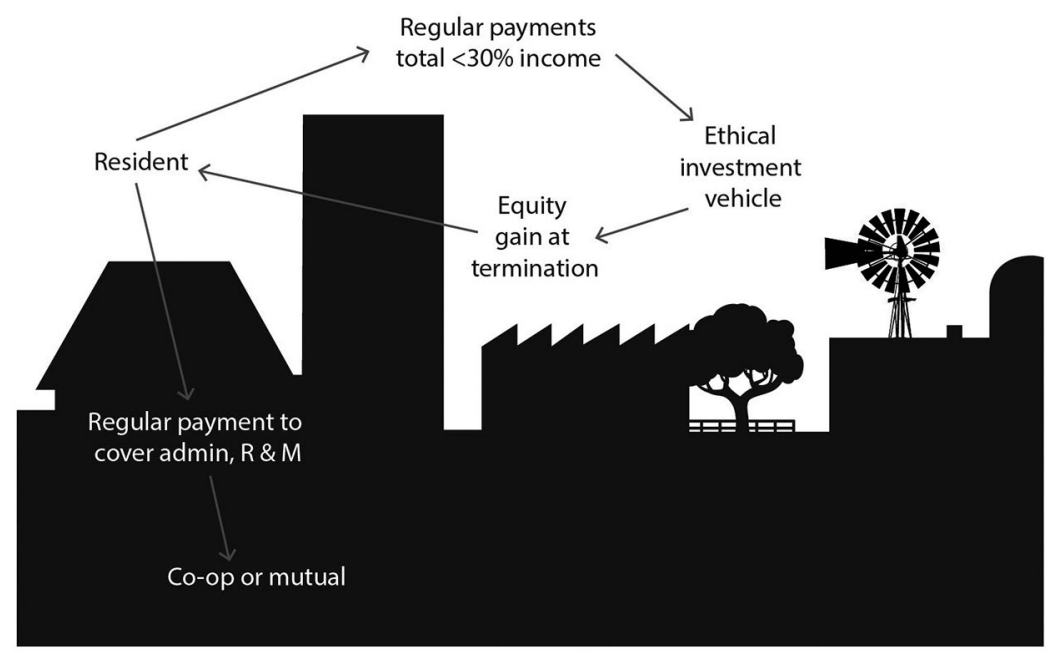

Fig. 17.3 Author's schematic of Stone's (2009) 'resident-saver' model Source: Author

This might be a highly appropriate model for Aboriginal and Torres Strait Islander communities, as it dislocates any equity investment and housing security from each other, and does not demand equity investment to secure long-term tenure; rather investment is an option for households if and as they have capacity. This creates an avenue for equity to be directed into appropriate community enterprises, which can operate at any scale. Further, the existence of a cooperative or mutual means that the resident's right to - and eligibility forhousing is not tied to an individual home, but rather to a unit within the organisation's stock, which can change. As allocations within the organisation's stock are made by the organisation, current mismatches between community housing allocation protocols and government allocation processes can be ameliorated, or hopefully avoided altogether. While currently a hypothetical model, this might be worth consideration for communities, and by policymakers with regard to the development of appropriate support mechanisms.

There are already innovative housing and investment activities emerging, such as the Kariyarra Mugarinya Joint Venture aiming to make housing available to resources companies through long-term leases, and channel the income to the development of affordable housing for community members (YMAC 2011, Massey 2012). There are also communities developing rent-to-buy schemes. However without 
appropriate controls, those might not provide the ongoing community role that many communities wish to see, and may ultimately lead to assets and land being lost from community or broader Aboriginal and Torres Strait Islander ownership. Given there is existing interest in diversifying tenure and enabling hybrid forms to underpin appropriate community stability and development, it would seem timely to explore and explain the mechanisms that can be developed to do so.

\section{Reflections: Recognising and enabling hybridity}

At a more conceptual level, models such as Stone's are interesting, as they start to identify and unpack the social and economic functions of housing tenure, and separate and allocate these amongst the multiple stakeholders involved in the creation and enactment of property. These multiple parties are hidden in dominant models of tenure, which default to either a singular owner, a precarious private renter, or a dysfunctional tenant of the state. All of these are simplistic erasures of the vast socioeconomic arrangements that make property comprehensible, or tenure possible. Erasing or denying diversity severely limits the options available or the relationships that can be articulated through tenure. Engaging with the relationality of property and fostering subsequent diversity in tenure raises the question of how this can be enabled by an appropriate, supportive policy framework. This requires a focus on principles rather than forms which, while requiring an awareness of and sensitivity to nuance, is possible. Such conceptualisations of tenure resonate with Altman's $(2007,2008,2009)$ focus on hybridity, as they focus on models discussed elsewhere in the housing literature as 'intermediate' tenures (e.g. Whitehead \& Monk 2011), that are seen to lie between owning and renting. Fig. 17.4 provides a possible reading of the intermediate tenure space. 


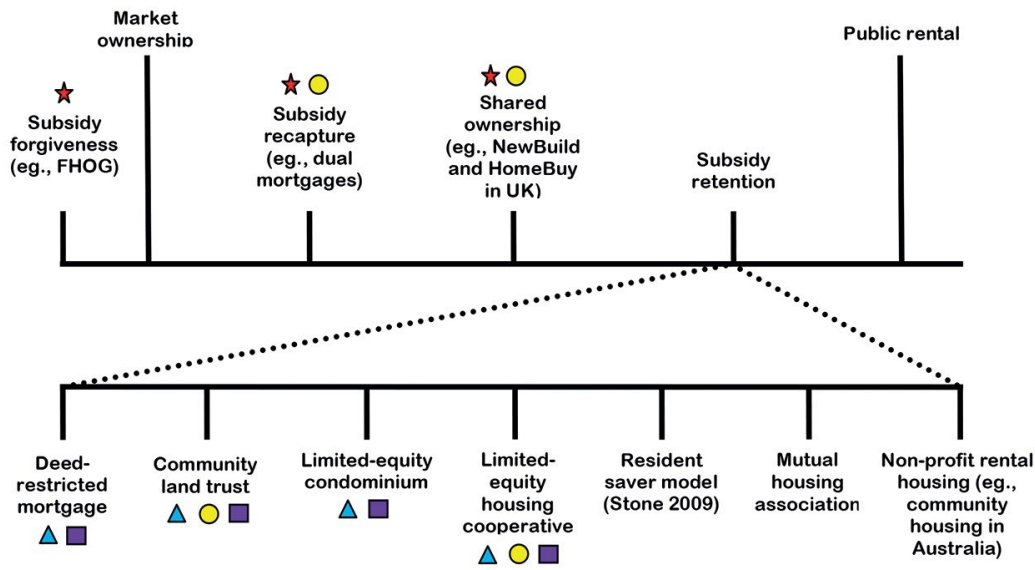

\footnotetext{
Key

Individual-based programs (after Curtin \& Bocarsly 2008)

$\triangle$ Property-based programs (after Curtin \& Bocarsly 2008)

Shared equity (after Pinnegar et al. 2009)

$\square$ Shared equity home ownership (after Davis 2006)
}

This key refers to programs or models covered by the stated authors. It is arguable that mutual housing associations and Stone's (2009) proposed resident-saver model could also be classified as shared equity home ownership.

Fig. 17.4 Spectrum of housing tenure models across the US, UK and Australia

Source: Crabtree et al. (2012)

Further, much recent work in legal geography is revealing and exploring the actual complexity of property, highlighting the critical relevance of this in work to appropriately identify, recognise, and empower First Nations' property relations (e.g. Blomley 2004, 2013, 2014). This can be seen as the translation of concerns for differencebased policy (e.g. Sanders 2010, Crabtree 2014), flexibility and selfdetermination (e.g. Altman et al. 2005) into legal property articulations. This has the potential to create tenures that reflect diverse community and household aspirations, which may or may not align with extant tenure forms. However, the point is not the resultant tenure form, but the deployment of an understanding of property as an articulation of diverse and hybrid social and material relations. Focusing on the relationality of property in such ways has the potential not only to enable diverse, appropriate tenures for Aboriginal and Torres Strait 
Islander communities, but also to develop tenure diversity across the broader housing system, which can speak to ongoing struggles for affordable and appropriate housing (Crabtree et al. 2012).

\section{References}

Altman JC (2007). In the name of the market? In Altman JC \& Hinkson $\mathrm{M}$ (eds), Coercive reconciliation: stabilise, normalise, exit Aboriginal Australia, Arena Publications Association, Melbourne.

Altman JC (2008). Submission to the Northern Territory Emergency Response Review, Topical Issue 10, Centre for Aboriginal Economic Policy Research, The Australian National University, Canberra.

Altman JC (2009). Beyond closing the gap: valuing diversity in Indigenous Australia, Working Paper 54, Centre for Aboriginal Economic Policy Research, The Australian National University, Canberra.

Altman JC, Gray MC \& Levitus R (2005). Policy issues for the Community Development Employment Projects scheme in rural and remote Australia, Discussion Paper 271, Centre for Aboriginal Economic Policy Research, The Australian National University, Canberra.

Blomley N (2004). Unsettling the city: urban land and the politics of property, Routledge, New York.

Blomley N (2013). Performing property: making the world. Canadian Journal of Law and Jurisprudence XXVI(I):23-48.

Blomley N (2014). The ties that blind: making fee simple in the British Columbia treaty process. Transactions of the Institute of British Geographers 40(2):168-79.

Crabtree L. (2014). Community land trusts and Indigenous housing in Australia: exploring difference-based policy and appropriate housing, Housing Studies 29(6):743-59.

Crabtree L, Blunden H, Phibbs P, Sappideen C, Mortimer D, ShahibSmith A \& Chung L (2013). The Australian community land trust manual, University of Western Sydney, Sydney. 
Crabtree L, Phibbs P, Milligan V \& Blunden H (2012). Principles and practices of an affordable housing community land trust model, Research Paper, Australian Housing and Urban Research Institute, Melbourne.

Crabtree L, Moore N, Phibbs P, Blunden H \& Sappideen C (2015). Community land trusts and Indigenous communities: from strategies to outcomes, Final Report No. 239, Australian Housing and Urban Research Institute, Melbourne.

Fagan M (2012). Towards privately financed property on Indigenous land in the Northern Territory, Final report of the Access to Finance on Indigenous land in the Northern Territory Project, prepared for the Department of Business, Northern Territory Government, Darwin.

FaHCSIA (Department of Families, Housing, Community Services and Indigenous Affairs) (2010). Indigenous home ownership issues paper, FaHCSIA, Canberra.

Massey A (2012). Joint venture aims to bring homes to market. North West Telegraph 12 December.

Memmott P, Moran M, Birdsall-Jones C, Fantin S, Kreutz A, Godwin J, Burgess A, Thomson L, \& Sheppard L (2009). Indigenous homeownership on communal title lands, AHURI Final Report No. 139, Australian Housing and Urban Research Institute, Melbourne.

Misak M (2009). National Community Land Trust Network 2008 foreclosure survey: report October 26, 2009, National Community Land Trust Network, Portland OR.

National CLT Network (2008). 2007 CLT Network foreclosure survey, National Community Land Trust Network, Portland OR.

Regional Development Australia (2014). Doors to ownership: a business case and guidelines for a shared homeownership scheme with NSW community housing associations, Regional Development Australia, Sydney.

Sanders W (2010). Ideology, evidence and competing principles in Australian Indigenous affairs: from Brough to Rudd via Pearson and the NTER. Australian Journal of Social Issues 45(3):307-31. 
Stone $M$ (2009). Housing and the financial crisis, paper presented to National Housing Researchers' Conference, Sydney, August 7-9.

Tauranga City Council (2013). Te Keteparaha Mo Nga Papakāinga. Māori Housing Toolkit, Tauranga City Council, Tauranga NZ.

Thaden E (2010). Outperforming the market: making sense of the low rates of delinquencies and foreclosures in community land trusts, National Community Land Trust Network, Portland OR.

Thaden E (2011). Stable home ownership in a turbulent economy: delinquencies and foreclosures remain low in community land trusts, Lincoln Institute of Land Policy, Cambridge.

Whitehead C \& Monk S (2011). Affordable home ownership after the crisis: England as a demonstration project. International Journal of Housing Markets and Analysis 4(4):326-40.

YMAC (2011). Kariyarra Joint Venture Corporation in land development deal, YMAC Blog, July 28, Yamatji Marlpa Aboriginal Corporation, Perth. 
This text is taken from Engaging Indigenous Economy: Debating diverse approaches, edited by Will Sanders, published 2016 by ANU Press, The Australian National University, Canberra, Australia. 